\title{
BIBCO Training and Its Influence on PCC Partnerships
}

\section{Kate Harcourt}

To cite this article: Kate Harcourt (2019): BIBCO Training and Its Influence on PCC Partnerships, Cataloging \& Classification Quarterly, DOI: 10.1080/01639374.2019.1696437

To link to this article: https://doi.org/10.1080/01639374.2019.1696437

Published online: 23 Dec 2019.

Submit your article to this journal ๘

Q View related articles $\sqsubset$

View Crossmark data \lceil 


\title{
BIBCO Training and Its Influence on PCC Partnerships
}

\author{
Kate Harcourt \\ Columbia University Libraries, Original and Special Materials Cataloging, New York, NY
}

\begin{abstract}
BIBCO is one of four programs in the PCC. This article summarizes the development of $\mathrm{BIBCO}$ and how its cataloging training program was strikingly different from the other three programs: NACO, CONSER and SACO. BIBCO grew out of the 1990-1991 recession which created widespread anxiety over the cost of original cataloging. BIBCO attempted to reduce the cost without sacrificing quality and increase record production through the use of core records. The early training emphasized the value of cooperation. PCC's strength in this area is seen today in its partnerships and leadership in metadata initiatives such as linked data.
\end{abstract}

\section{ARTICLE HISTORY}

Received August 2019

Revised November 2019

Accepted November 2019

\section{KEYWORDS}

Cataloging training; PCC Core records; original cataloging; partnerships; cataloging

The Monographic Bibliographic Record Cooperative Program (BIBCO) was not the first attempt to establish a cooperative program to create MARC records. The short-lived National Coordinated Cooperative Program (NCCP) anticipated BIBCO in the late 1980s. The NCCP consisted of twelve libraries creating bibliographic records according to Library of Congress (LC) specifications. The Program required extensive training at LC in LC cataloging procedures, the use of LC's Multiple Use MARC System (MUMS), and there were high telecommunications costs for participating libraries. The NCCP proved to be unsustainable for these reasons and in response, the Cooperative Cataloging Council (CCC) brought together cataloging experts to develop a vision for cooperative cataloging that would be cost-effective, low barrier, and inclusive. Their work was heavily influenced by the 1990-1991 recession which created a sluggish economy and a high rate of unemployment that persisted through much of the 1990s and consequently created anxiety over the high cost of original cataloging. The CCC formed the Program for Cooperative Cataloging (PCC) by bringing together the Cooperative Serials Program (CONSER) and the Name Authority Cooperative Program (NACO), both of which began in the 1970s, and creating the BIBCO and Subject Authority Cooperative Program (SACO) programs. The goal was to form a coalition 
of public, academic, and special libraries of all sizes that would work together to produce high quality bibliographic and authority records under mutually accepted standards. Now, twenty-five years later, we celebrate this vision.

The most obvious outcome of the work of the CCC was the 1994 development of the core record standard for monographs. ${ }^{1}$ The core record was designed to be the default cataloging standard and was intended to provide lower-cost cataloging that met agreed upon community standards. Unlike minimal records, core records are supported by national level authority records and were created by fully trained BIBCO catalogers. Core records were considered a floor, not a ceiling and metadata could be added according to cataloger judgment until the point at which a record could be coded as full level. Both core and full level BIBCO records contain call numbers from an established classification system and subject headings from an established thesaurus at the appropriate level of specificity. BIBCO records use "pcc" as the authentication code in the MARC 042 field so they could be easily identified and integrated smoothly into copy cataloging workflows.

$\mathrm{BIBCO}$ differed from the other programs in that its training program was never as rule intensive as CONSER, SACO, or NACO. It was assumed that catalogers knew how to catalog according to the second edition of the AngloAmerican Cataloging Rules (AACR2) and the Library of Congress Rule Interpretations (LCRIs). Instead, BIBCO training sought to create a new cataloging culture and a new kind of cataloger. It was also very much a product of its time. BIBCO grew out of a need to increase bibliographic record production which was exacerbated by economic uncertainty, shrinking budgets, and pessimism about the future of cataloging in an increasingly automated world. BIBCO was seen as the way to reconceptualize cataloging and make better use of highly trained professional catalogers. BIBCO sought to empower catalogers to work together to substantially increase the availability of quality records using accepted standards. BIBCO's message, however, was not without controversy. The call to streamline cataloging by making it "more, better, cheaper, faster" 2 by using core level records was sometimes seen as a devaluation of cataloging expertise.

Although BIBCO did not require much cataloging training, participation did entail a substantial commitment from catalogers and administrators. There were two prerequisites: NACO independence and OCLC National Level Enhance status in each format used by a library in its PCC cataloging. National Level Enhance was created for the PCC by OCLC in September 1994. The status was granted by OCLC after record review and it allows PCC libraries to lock, edit, and replace any record in WorldCat, including Library of Congress records. ${ }^{3}$ The ability to correct and enhance OCLC records was a powerful incentive to join BIBCO. 
Some of the first BIBCO training scripts were developed by the author of this article and Susan Summer and were made available on the PCC home page. The last versions of those early scripts and handouts are archived in the Wayback machine. ${ }^{4}$ Training was customized for each institution based on pre-training surveys and held onsite over two to three days. The training, with its emphasis on cataloging values and group exercises to define quality, perhaps seems simplistic and quaint in 2019. The Values Clarification exercise, for example, was meant to elicit discussion on how cataloging practice needed to change to meet the economic realities of the time. Participants were asked:

- What are five to ten characteristics of the climate in which libraries operate today?

- What do user communities and funding agencies expect from libraries today?

- What are some of the new/different things libraries, including catalogers, have done/are doing to meet expectations within the current climate?

These questions were followed by exercises to determine cultural values needed for a contemporary cataloging culture to be successful and the new role of catalogers in meeting the concerns of the user community.

It is useful to step back and remember that until the PCC, catalogers adhered strictly to cataloging rules and rule interpretations sometimes at the expense of timely access to material. The advent of online catalogs put a spotlight on backlogs and the internet demanded new ways of thinking about structuring metadata. For example, was it necessary to agonize over choice of main entry? It also became increasingly hard to justify waiting for LC records and there was growing urgency to produce more quality copy cataloging. Much of the training focused on empowering catalogers to use judgment to solve bibliographic problems and to increase efficiency. The minutes of the BIBCO Operations Meeting held in May 1998 describe the new environment as one where catalogers are "producing cataloging records that exemplify usability, quality, dependability, responsiveness, timeliness, and the dynamic nature of the core record. The traits valued in catalogers include cooperation, innovation, trust/respect, humor, collegiality, ability, flexibility, cataloger's judgment, diversity, communication, reliability, creativity, and empowerment." ${ }^{5}$ Some specific goals in the early training script included:

1. Understanding the value of cataloging cooperation. For many, thinking outside of one's own organizational structure was new, exciting, and challenging. The training emphasized that the Library of Congress is an 
equal partner in a collective effort to increase the world record pool. All PCC participants were charged with increasing record production and making cataloging records available for use and enhancement through the bibliographic utilities.

2. Understanding that the mandate to increase production does not come at the expense of quality. The PCC worked hard to agree upon a mutually acceptable standard for its records. It was recognized that the machine environment made accurate description even more crucial. The core record was the default for PCC cataloging. The core record was fuller than minimal but many note fields were optional, especially those which served only to justify access points. All authorized access points were supported by authority records.

3. Understanding that timeliness and cataloger judgment are components of quality. Consultation with public services on priorities and record fullness was encouraged and new for many catalogers.

4. Recognizing that the PCC is a highly democratic organization with a goal of becoming international in scope, governance was structured to foster communication and membership input. BIBCO and CONSER Operations Committees supported the needs of catalogers and encouraged the sharing of efficient workflows and the PCC Policy Committee supported policy making and management of the Program. The Standing Committees on Training, Standards, and Automation were formed to promote training, effective use of technology, and standards development by and for the membership.

5. Understanding the special coding required by the core record standard, the requirement to back up all access points with authority records, and how to decide whether to apply the core record standard or create a full cataloged record using judgment or institutional priorities. Columbia, for example, used core level as the default but consulted with selectors on their needs for metadata above the core standard for specific categories of material. Landmark Preservation Reports for the Avery Art and Architecture Library, for example, received full level cataloging to support the needs of Columbia's architecture program.

In addition to onsite training, there were numerous outreach efforts. BIBCO trainers spoke at local and national conferences. BIBCO trainers served on the faculty of Cataloging Now Institutes. These were half-day sessions held at non-BIBCO libraries and were intended to promote the values of the PCC and the core record. The audience for the Institutes included catalogers, technical service administrators, and public service librarians. BIBCO also grew through extensive use of the train-the-trainer model. The burden of training and documentation rested with all PCC 
members, not just the Library of Congress. Special training efforts such as series training could efficiently be taken on by community experts. The first trainers mentored other trainers, often by training in tandem and much effort was put into developing trainer and participant manuals with extensive record samples and tip sheets. The manuals were available to all catalogers on the PCC website and were used in library schools. Trainers developed collegial relationships with the catalogers they trained. Trainers reviewed records, certified independence from review, and stayed on call for questions and advice.

On January 4, 2010, the PCC replaced the full and core record standards with the single BIBCO Standard Record (BSR). The core record standard had never been fully accepted and requiring catalogers to make the distinction between core and full could be time consuming and sometimes contentious. Leaving out a bibliography note in order to meet a local mandate to create core records created cynicism and undermined the PCC's endorsement of cataloger judgment. The BIBCO Annual Report for FY2010 noted that for years the annual BIBCO record statistics included twice as many full level records as core level records defeating the goal of creating more records. ${ }^{6}$ The BSR, like the core record, was designed to create more cataloging in a cost-effective in a way but the message was more palatable to catalogers. The BSR was also described as a floor not a ceiling but it was presented as a way to meet the FRBR (Functional Requirements of Bibliographic Records) user tasks to find, identify, select, and obtain. The BSR retained the values of cataloger judgment, favoring access points with authority control over description, and consideration of the needs of the local institution.

In thinking back on my experience as a BIBCO trainer, it strikes me how many of the values embedded in the early BIBCO training program led to the success of the PCC and are still relevant today. The work to create a new cataloging culture and a new kind of cataloger was successful and has paid off as we move away from creating PCC-branded MARC records into the new world of linked data. Over two decades of working cooperatively has developed a cadre of collegial, innovative, and dedicated metadata experts within the PCC community who are well suited to take advantage of new opportunities to collaborate with each other and with other organizations. We have created an organization positioned to seek out opportunities to form new partnerships and collaborative ventures. It was not a great stretch to use our PCC skills to form partnerships with the International Standard Name Identifier (ISNI) Agency or to participate in the Linked Data for Production (LD4P) Mellon grant or in the SHARE Virtual Discovery Environment (SHARE-VDE). Collaboration is natural for PCC catalogers and there have been repeated instances of PCC libraries 
creating formal or informal alliances for mutual greater good. 2CUL, for example, made use of the trust in PCC that had developed between catalogers at Cornell University Library and Columbia University Libraries. That, and our experience in library cooperation, made this more radical collaboration seem possible. PCC libraries have been strongly represented in initiatives and organizations such as Borrow Direct, Ivy Plus, the International Federation of Library Associations and Institutions (IFLA), Resource Description and Access (RDA) development, Association for Library Collections and Technical Services (ALCTS) (especially the Committee on Cataloging: Description and Access [CC:DA]), and OCLC's FAST Policy and Outreach Committee (FPOC). The PCC's reputation for quality metadata, standards development, and training gives it the power to influence matters of mutual interest such as FRBR or the IFLA Library Reference Model (LRM). It is no longer unusual to have a grant-making agency ask for PCC endorsement or participation. One of the first requests came from the Institute of Museum and Library Service (IMLS). The IMLS grant for a National Strategy for Shareable Local Name Authorities was awarded to Cornell University Library, in partnership with LC, OCLC, PCC, the ORCID organization, the Coalition for Networked Information (CNI), the Social Networks and Archival Context Cooperative (SNAC), the BIBFLOW project, Stanford University Library, and Harvard Library. PCC's role in the grant was significant. Chew Chiat Naun (Standing Committee on Standards Co-Chair) was the Principal Investigator, and Michelle Durocher (PCC Policy Committee and ISNI) and Nancy Lorimer (member of the PCC URI Task Force and SACO Music Coordinator) were core participants. Steven Folsom (Chair, PCC Linked Data Advisory Committee) played a significant role in preparing the proposal. Isabel Quintana served as the PCC liaison to the grant team and was charged with sharing findings with the PCC membership. This type of partnership is encoded in our Strategic Initiatives in the directive to "broaden our scope to be more diverse, inclusive, and collaborative with metadata creators in research and cultural heritage communities and with other agencies and project partners." 7

At this twenty-five-year juncture, we can indeed celebrate that cooperation for the sake of economic survival has grown into partnerships for information discovery undreamed of when the PCC began.

\section{Notes}

1. "BIBCO Core Records Standards [Superseded by the BIBCO Standard Record, Oct. 1, 2010]," accessed August 21, 2019, https://www.loc.gov/aba/pcc/bibco/core-recordstandard.html

2. BIBCO, “BIBCO Operations Committee Meeting. Values Statement," May 7-8, 1998, accessed August 21, 2019, https://www.loc.gov/aba/pcc/bibco/bibcomeeting98.html 
3. OCLC, "Guidelines for National Level Enhance Participants," accessed August 21, 2019, https://www.oclc.org/support/services/worldcat/documentation/records/enhanceguidelines. en.html

4. "Training scripts and local BIBCO policy documents (via Columbia University)," on BIBCO homepage January 3, 2008. Accessed August 21, 2019 through Internet Archive https://web. archive.org/web/20080201000706/; http://www.loc.gov/catdir/pcc/bibco/bibco.html

5. BIBCO, "BIBCO Operations Committee Meeting. Values Statement."

6. “BIBCO Annual Report FY2010,” accessed November 7, 2019, https://www.loc.gov/aba/pcc/ bibco/documents/BIBCOAnnualReportFY2010.pdf

7. "PCC (Program for Cooperative Cataloging) Strategic Directions, January 2018-December 2011," revised January 24, 2019, https://www.loc.gov/aba/pcc/about/PCC-StrategicDirections-2018-2021.pdf 